\title{
Cross-sectional Porosity and Oil Sorption of PLA Nanofibers with Hollow and Lotus Root-like Structures
}

\author{
Ai-Yun Jiang ${ }^{a}$, Zhi-Juan Pan ${ }^{\text {a,b,* }}$ \\ ${ }^{a}$ College of Textile and Clothing Engineering, Soochow University, Suzhou, Jiangsu 215123, China \\ ${ }^{\mathrm{b}}$ National Engineering Laboratory for Modern Silk, Suzhou, Jiangsu 215123, China
}

\begin{abstract}
Lotus root-like fibers and hollow structure fibers have been extensively studied in many different fields due to a large specific surface area and high porosity. However, most of the prepared materials have only one lotus root-like or hollow structure. Here, in this paper, the coaxial electrospinning poly(lactic acid) (PLA) nanofibers had hollow and lotus root-like structures. The porosity of the cross section was quantitatively analysed by MATLAB, and the oil sorption experiment was also carried out. In the hollow structure, when the flow rate ratio of the core/shell solution was 1:2 or 1:4, the pore porosity was about $41 \%$, larger than $34.88 \%$ (1:3), while the pore porosity at $19-22 \mathrm{kV}$ was stable at about $41 \%$ $\pm 2 \%$. On the contrary, the lower the porosity, the better the spinning state and the higher the hollow ratio. In the lotus root-like fibers, the porosity values were about $23 \% \pm 2 \%$ under different spinning conditions, which means that the lotus root-like porosity was not significantly affected by the flow rate ratio of core/shell solution and voltage. Meanwhile, the absorption capacity of the lotus root-like fibers to diesel oil is more than 1.5 times that of hollow fibers.
\end{abstract}

Keywords: Coaxial Electrospinning; Hollow and Lotus Root-like Structures; Porosity; Oil Sorption

\section{Introduction}

Poly(lactic acid) (PLA) is considered to be one of the most promising renewable, green and environmental friendly material. Starch, which is the raw material, can be extracted from some plants such as corn, wheat, and cassava. Enzymes break down to produce glucose, and the lactic acid bacteria are fermented to become lactic acid. When lactic acid is added with catalyst at high temperature and low pressure, poly(lactic acid) (PLA) can be directly synthesized by condensation polymerizations [1-8].

Nowadays, the oil spill on the sea surface is one after another, which has a serious impact on ecological environment. Due to its advantages of high efficiency and no secondary pollution, nanofiber membranes have unique advantages in oil/water adsorption [8-12], and gradually become the subject of study.

\footnotetext{
${ }^{*}$ Corresponding author.

Email address: zhjpan@suda.edu.cn (Zhi-Juan Pan).
} 
In the present study, poly(lactic acid) (PLA) nanofibers with hollow [13-14] and lotus-root-like [15-17] structures were prepared using the coaxial electrospinning method [18-19]. To achieve this goal, the prepared PLA/PVA nanofibers with a core/shell structure were immersed in deionized water for $48 \mathrm{~h}$ to remove the core (PVA). The cross-sectional porosities of the prepared nanofibers were analysed quantitatively using MATLAB, and the oil sorption experiments were also performed. The results of the porosity analyses show that, for the hollow structure, when the flow rate ratio of the core/shell solution was 1:2 or 1:4, the cross-sectional porosity was about $41 \%$, larger than $34.88 \%$ (flow rate ratio $=1: 3$ ). However, the cross-section porosity seemed to be voltage-independent, which was demonstrated by the fact that the porosity was stable at $41 \% \pm 2 \%$ when the voltage varied in the range of $19-22 \mathrm{kV}$. While in the lotus-root-like fibers, the porosity value was not affected by these parameters. The results of the oil sorption experiments demonstrated that the absorption capacity of the lotus-root-like structure fibers to diesel oil is more than 1.5 times that of the hollow structrue fibers.

\section{Materials and Experiments}

\subsection{Materials}

PLA $\left(\mathrm{Mw}=1.0 \times 10^{5} \mathrm{~g} / \mathrm{mol}\right)$ was purchased from Zhejiang Hai Zheng Biological Materials Co., Ltd., Zhejiang, China. PVA $\left(\mathrm{Mw}=9.5 \times 10^{4} \mathrm{~g} / \mathrm{mol}\right.$, percent hydrolyzation $\left.95 \%\right)$ was purchased from J\&K scientific Co., Ltd., Beijing, China. N, N- Dimethylacetamide (DMAC), Dichloromethane (DCM) and Dimethyl sulfoxide (DMSO) were purchased from National Medicine Group Chemical Reagents Co., Ltd., Beijing, China. Diesel oil was obtained from Suzhou Difite Filtration Technology Co., Ltd., Suzhou, China. All chemicals were of analytical grade and used without further purification.

\subsection{Preparation of PLA Nanofibers with Hollow and Lotus-root-like Structures}

8 wt.\% PLA was dissolved in a DCM/DMAC (mass ratio of 10:1, w/w) mixed solvent, 2 wt.\% PVA was dissolved in DMSO, and DCM was added to the PVA/DMSO solution (where the DMSO/DCM ratio was 2:1, w/w) after PVA was completed dissolved. Then both of them stirred at room temperature for about $12 \mathrm{~h}$. Two $5 \mathrm{~mL}$ syringes were used-one to absorb the shell solution (PLA) and the other to absorb the core solution (PVA or PLA), and then fixed onto two syringe pumps (KDS-100, KD Scientific, Inc., Holliston, MA, USA). The general setup of the apparatus is shown in Fig. 1. Tubes were used to connect the syringes and the coaxial needle, and a high-voltage power supply (DWP503-1ACDF, Tianjin Dongwen High Voltage Co., Tianjin, China) was connected to the coaxial needle through a wire.

The electrospun PLA/PVA or PLA/PLA composite nanofiber membrane was deposited onto the metallic roller, which was positioned $12 \mathrm{~cm}$ from the needle tip. Meanwhile the relative humidity $(\mathrm{RH})$ of the environment was $45 \% \pm 3 \%$. PLA nanofibers with hollow and lotus-rootlike structures were prepared by adjusting the flow rate ratio of core/shell solution $(0.3 \mathrm{~mL} / \mathrm{h}: 0.6$ $\mathrm{mL} / \mathrm{h}(1: 2), 0.3 \mathrm{~mL} / \mathrm{h}: 0.9 \mathrm{~mL} / \mathrm{h}(1: 3)$ and $0.3 \mathrm{~mL} / \mathrm{h}: 1.2 \mathrm{~mL} / \mathrm{h}(1: 4))$ and spinning voltage $(19$ $\mathrm{kV}, 20 \mathrm{kV}, 21 \mathrm{kV}, 22 \mathrm{kV}$ and $23 \mathrm{kV}$ ). The control sample which only has lotus-root-like structure 


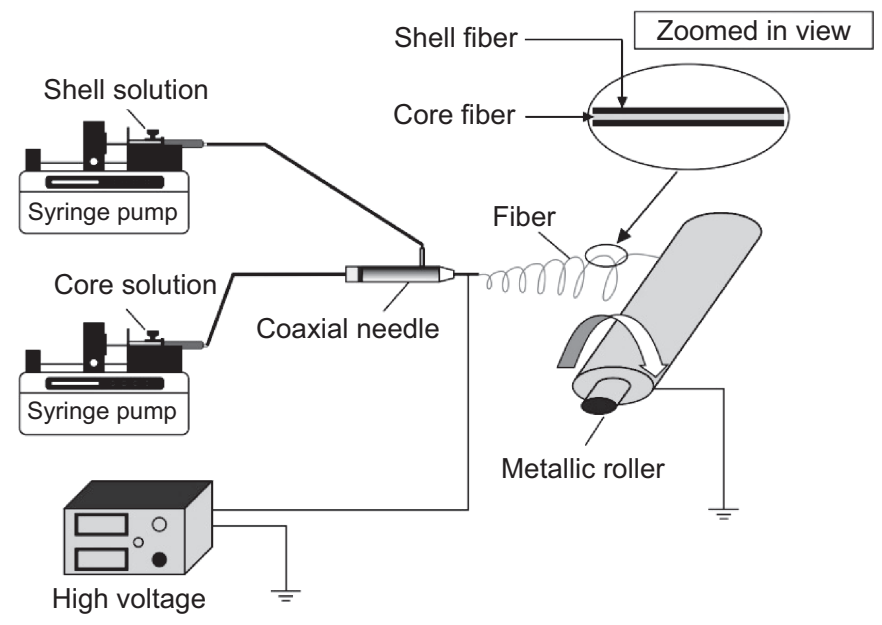

Fig. 1: Schematic of coaxial electrospinning apparatus

was prepared at the flow rate ratio of $0.3 \mathrm{ml} / \mathrm{h}: 0.9 \mathrm{ml} / \mathrm{h}$ (core/shell solution $=\mathrm{PLA} / \mathrm{PLA})$ and the voltage was $23 \mathrm{kV}$. The distance and the $\mathrm{RH}$ of the environment were the same as before (12 $\mathrm{cm}$ and $\mathrm{RH}$ of $45 \% \pm 3 \%$ ).

In order to obtain PLA nanofibers with hollow and lotus-root-like structures, it was necessary to remove the core (i.e. PVA) fibers in the PLA/PVA composite nanofibers. To this end, the shell/core PLA/PVA nanofiber membrane was soaked in deionized water; this deionized water was required to be replaced about every $2 \mathrm{~h}$ for a total duration of $48 \mathrm{~h}$. Finally, hollow PLA fibers were obtained after drying in a vacuum drying oven at $35^{\circ} \mathrm{C}$ for $12 \mathrm{~h}$.

\subsection{Preparation of Cross-section}

The nanofiber membrane was cut into a rectangle $(30 \mathrm{~mm} \times 5 \mathrm{~mm})$, which was fixed on two slides that were separated by a distance of $5 \mathrm{~mm}$. The fiber cross-section, as shown in Fig. 2, can be achieved after the nanofiber membrane in liquid nitrogen for about 1 minute. The cross-section of the hollow PLA nanofiber membrane was observed using FE-SEM (S-4800, Hitachi Ltd. Tokey, Japan).

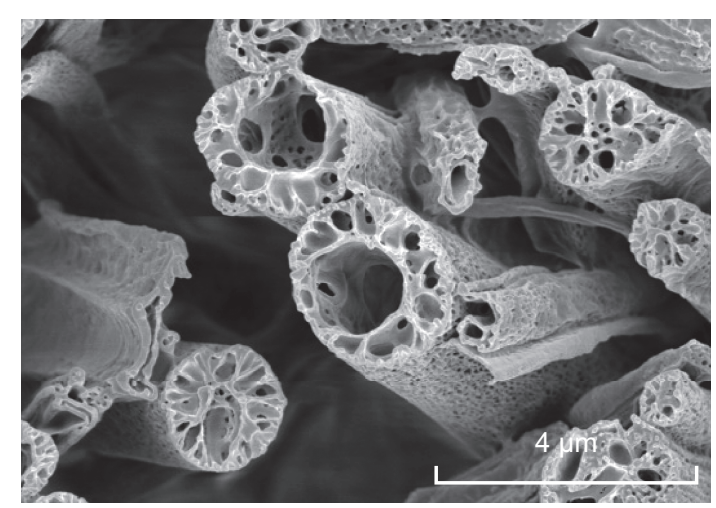

Fig. 2: FE-SEM image of PLA nanofibers' cross-section 


\subsection{Cross-sectional Porosity}

The cross-sectional porosity of the porous PLA nanofibers, which included the hollow and lotusroot-like structures, was calculated.

First, Photoshop was used to cut out a rectangular section (depicting either the hollow or lotusroot-like structure) of the FE-SEM image, which was then input into the programmed MATLAB to obtain the desired results: a binarized image of the total cross-sectional area, a binarized graph of a lotus-root-like or a hollow structure, and a data sheet of the ratio of every single pore area to total cross-sectional area (the largest ratio corresponds to the hollow porosity, and when the single pore area ratio is less than $0.2 \%$, it well be eliminated). The total cross-sectional porosity $\left(S_{p}\right)$ is equal to the sum of each small porosity $\left(S_{1}, S_{2}, \cdots, S_{n}\right)$, and the ratio of the hollow porosity to the pore porosity is denoted as $\mathrm{R}$. That is,

$$
\begin{gathered}
S_{p}=S_{1}+S_{2}+\cdots+S_{n} \\
R=\text { Hollow porosity/Pore porosity }
\end{gathered}
$$

Under the same electrospinning conditions, porosity of hollow and lotus-root-like fibers measured 10 FE-SEM images, the maximum and minimum measured values were discarded, and the rest were averaged.

\subsection{Oil Sorption Test}

The control sample (with lotus-root-like structure) and the PLA nanofiber membranes prepared at $19 \mathrm{kV}$ (with hollow and lotus-root-like structures) were subjected to an oil sorption test. $50 \mathrm{~g}$ of diesel oil was poured into a $100 \mathrm{~mL}$ beaker. The dried nanofiber membranes were immersed in the diesel oil. After 30 minutes, the fiber membrane was taken out from the beaker and dripped by its own gravity for 1 minute. The diesel oil sorption capacity was measured 6 times to calculate the average value.

The oil sorption capacity was calculated as follows:

$$
Q=\left(M_{1}-M_{0}\right) / M_{0}
$$

where, $Q$ is the oil sorption capacity $(\mathrm{g} / \mathrm{g}), M_{0}$ is the original mass of the fiber membrane and $M_{1}$ is the mass after oil sorption for 30 mins.

\section{Results and Discussion}

\subsection{Hollow Structure}

From Fig. 3, the FE-SEM images, the binarization of the total cross-sectional area, the binarization of porous structure, and the binarization of hollow structure at different feed rate ratio of core/shell solution can be visually watched. It can be clearly observed that both the fiber cross section and the hollow pores are irregular and tend to be elliptical in shape, and that there is a circle of elliptical holes on the elliptical ring with a certain thickness at the same time. The spacing between coaxial needle can ensure that the shell and core spinning liquid do not dissolve 
in the needle channel. The shell and core layers spinning liquid jointly formed a jet, and shell/core nanofibers (PLA/PVA) were ejected from Taylor cone. Removing the core (i.e. PVA) fibers in the PLA/PVA composite nanofibers can get hollow structure.

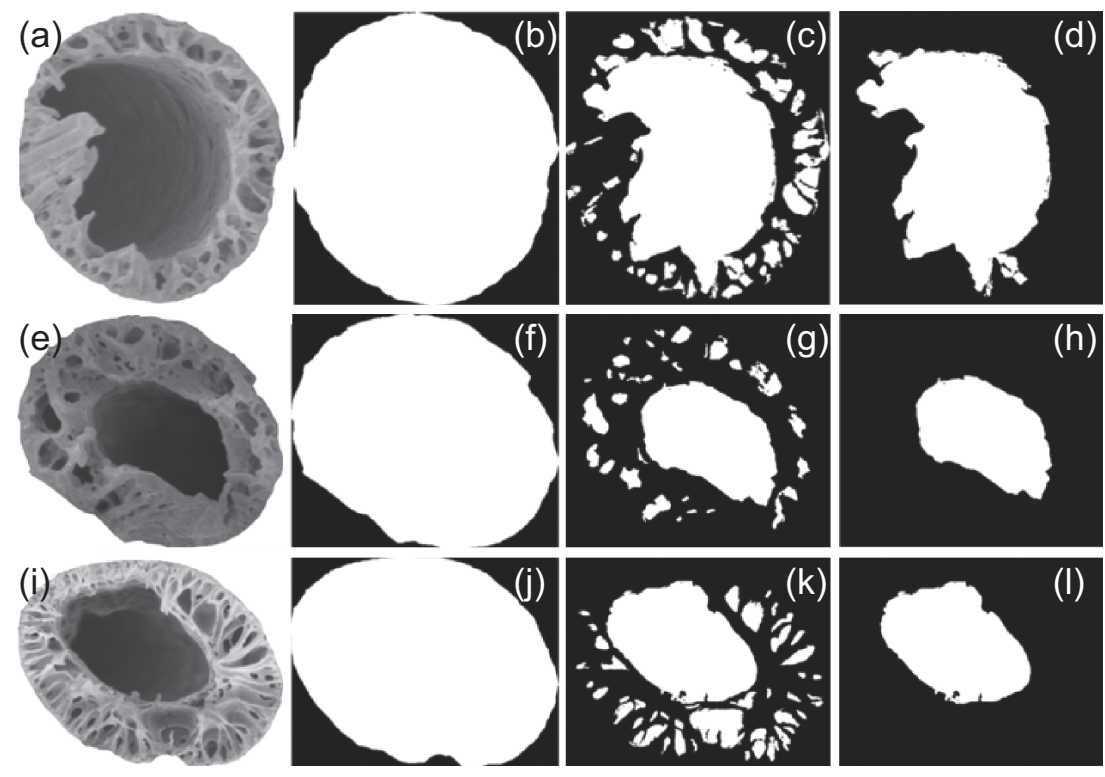

Fig. 3: Original (FE-SEM) and binarization of the cross-section with different feed rate ratio of core/shell solution, ( $\mathrm{a}, \mathrm{b}, \mathrm{c}, \mathrm{d}): 1: 2 ;(\mathrm{e}, \mathrm{f}, \mathrm{g}, \mathrm{h}): 1: 3$; and $(\mathrm{i}, \mathrm{j}, \mathrm{k}, \mathrm{l}):$ 1:4. (a, e, i): FE-SEM images; (b, f, j): binarized images of total area of cross-section; $(c, g, k)$ : binarized images of porous structure; and $(\mathrm{d}$, $\mathrm{h}, \mathrm{l})$ : binarized images of hollow structure

As can be seen from Table 1, when the flow rate ratio of core/shell solution was 1:2 or 1:4, the pore porosity was about $41 \%$, larger than $34.88 \%$ (1:3). Analyzing its reason may be spinning state at 1:3 was the most stable, the number of hollow fiber roots was also more, and hollow fibers were uniform, unlike the other two parameters which spun several extremely large hollow fibers.

Table 1: Cross-sectional porosity of hollow fibers fabricated with different feed rate ratio of core/shell solution

\begin{tabular}{ccccc}
\hline Samples & Pore Porosity/\% & Hollow Porosity $/ \%$ & R/\% & Number of Small Pores \\
\hline $1: 2$ & $42.68 \pm 7.31$ & $32.38 \pm 6.67$ & 75.87 & $12 \pm 2$ \\
$1: 3$ & $34.88 \pm 6.41$ & $26.64 \pm 8.40$ & 76.38 & $10 \pm 4$ \\
$1: 4$ & $40.45 \pm 5.24$ & $32.44 \pm 6.69$ & 80.20 & $13 \pm 4$ \\
\hline
\end{tabular}

Fig. 4 shows the case of electrospinning at different high voltages. In Table 2, the pore porosity at $23 \mathrm{kV}$ was the lowest, being $34.88 \% \pm 6.41 \%$, and the pore porosity at other voltages was about $41 \% \pm 2 \%$. The reason was that the voltage at $23 \mathrm{kV}$ was too high to electrospinning.

According to Table 1 and Table 2, when the spinning state was stable, the number of hollow fiber roots was large and the size was even, its $\mathrm{R}$ value was about $75 \% \pm 5 \%$ and the little pore number was about $12 \pm 2$. It can be seen that the hollow structure of PLA nanofiber prepared in this experiment has general characteristics. 


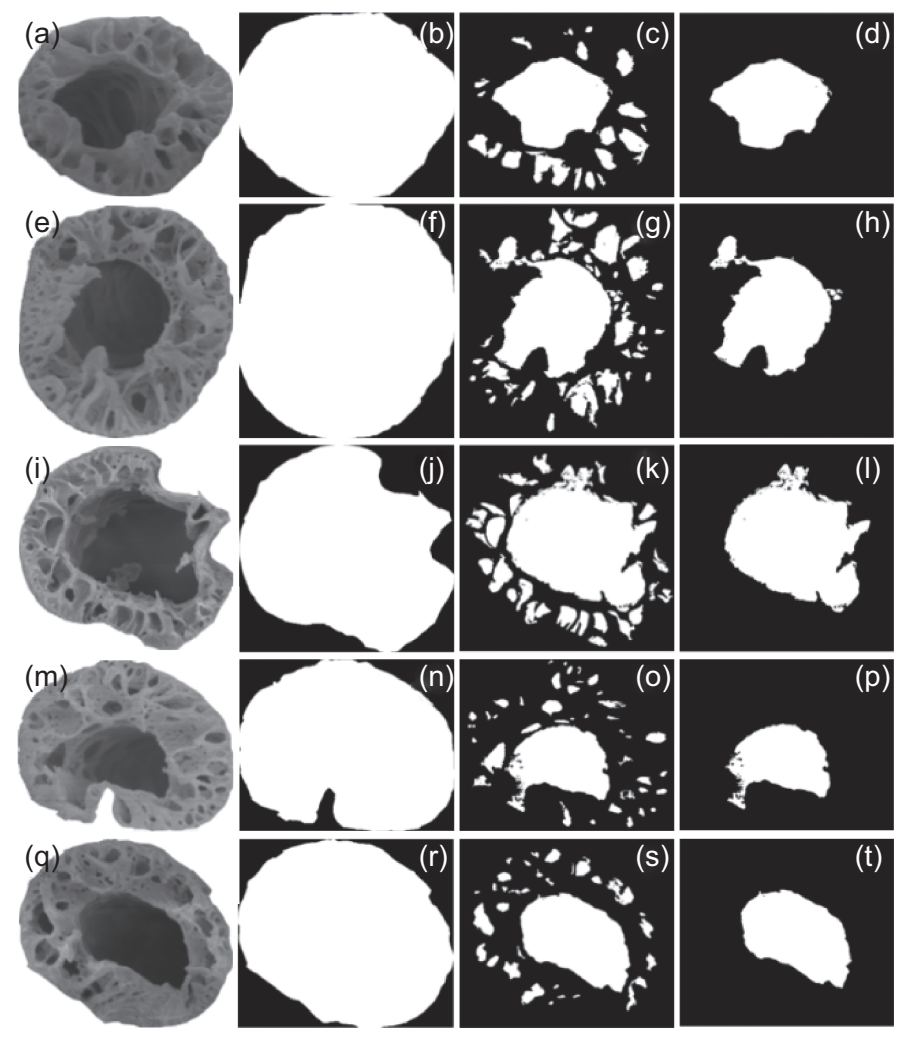

Fig. 4: Original (FE-SEM) and binarization of the cross-section with different high voltages, (a, b, c, d): $19 \mathrm{kV} ;(\mathrm{e}, \mathrm{f}, \mathrm{g}, \mathrm{h}): 20 \mathrm{kV}$; (i, j, k, l): $21 \mathrm{kV} ;(\mathrm{m}, \mathrm{n}, \mathrm{o}, \mathrm{p}): 22 \mathrm{kV}$; and (q, r, s, t): $23 \mathrm{kV}$. (a, e, i, m, q): FE-SEM images; (b, f, j, n, r): binarized images of the total area of the cross-section; (c, g, k, o, s): binarized images of porous structure; $(\mathrm{d}, \mathrm{h}, \mathrm{l}, \mathrm{p}, \mathrm{t})$ : binarized images of hollow structure

Table 2: Cross-sectional porosity of hollow fibers fabricated with different high voltages

\begin{tabular}{ccccc}
\hline Samples & Pore Porosity/\% & Hollow Porosity/\% & R/\% & Number of Small Pores \\
\hline $19 \mathrm{kV}$ & $40.48 \pm 5.92$ & $28.30 \pm 3.12$ & 69.91 & $12 \pm 1$ \\
$20 \mathrm{kV}$ & $39.84 \pm 8.28$ & $29.55 \pm 10.17$ & 74.17 & $14 \pm 3$ \\
$21 \mathrm{kV}$ & $43.46 \pm 5.67$ & $34.78 \pm 4.64$ & 80.03 & $14 \pm 3$ \\
$22 \mathrm{kV}$ & $39.88 \pm 8.42$ & $31.87 \pm 8.59$ & 79.91 & $12 \pm 2$ \\
$23 \mathrm{kV}$ & $34.88 \pm 6.41$ & $26.64 \pm 8.40$ & 76.38 & $10 \pm 4$ \\
\hline
\end{tabular}

\subsection{Lotus-root-like Structure}

As shown in Fig. 5 and Fig. 6, the PLA nanofiber with hollow structure prepared in this paper also has a lotus-root-like structure, because the proportion of hollow fiber in this research less than 100\%, and the non-hollow fiber was neat PLA nanofiber. Relevant studies shown, it can obtain porous nanofibers with either internal porosity or surface roughness by electrospinning a kind of hydrophobic polymer from a volatile and water-compatible solvent at a proper level of relative humidity [19]. The pores inside the fibers were formed by the volatilisation of the spinning solution and also by thermally induced phase separation.

It can be found from Table 3 and Table 4 that the porosity values of the lotus-root-like fibers prepared under different parameters did not change much, about $23 \% \pm 2 \%$. This indicates that 


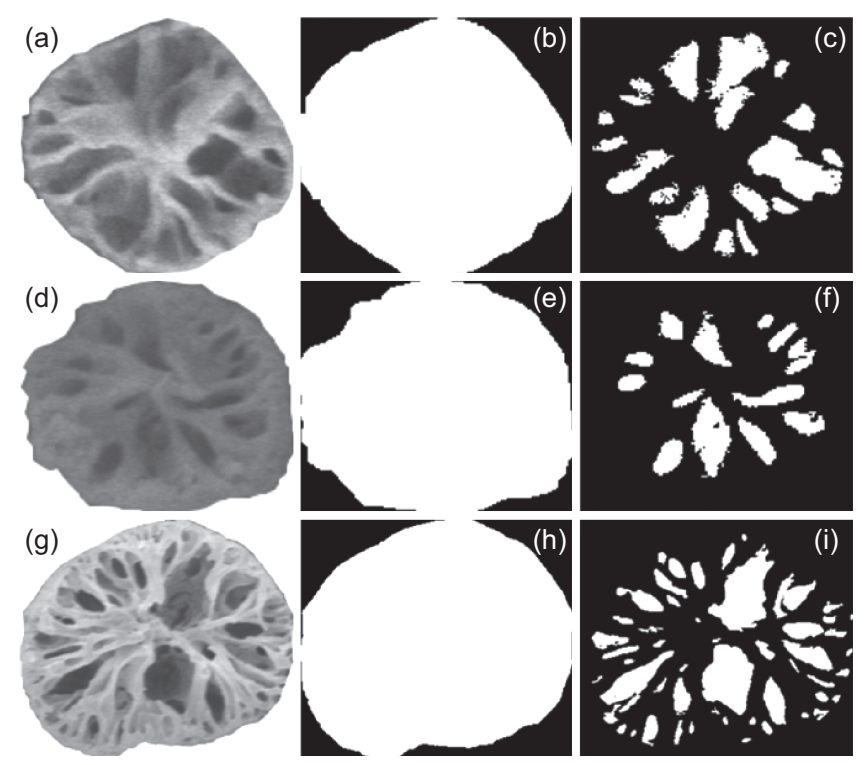

Fig. 5: Original (FE-SEM) and binarization of the cross-section with different feed rate ratio of core/shell solution, (a, b, c): 1:2; (d, e, f): 1:3; and (g, h, i): 1:4. (a, d, g): FE-SEM images; (b, e, h): binarized images of the total area of the cross-section; $(c, f, i)$ : binarized images of porous structure

Table 3: Cross-sectional porosity of lotus-root-like fibers fabricated with different feed rate ratio of core/shell solution

\begin{tabular}{cccc}
\hline Samples & Lotus root-like Porosity $/ \%$ & Standard Deviation $/ \%$ & CV $/ \%$ \\
\hline $1: 2$ & 24.63 & 4.29 & 17.43 \\
$1: 3$ & 23.02 & 4.10 & 17.82 \\
$1: 4$ & 25.22 & 3.21 & 12.74 \\
\hline
\end{tabular}

Table 4: Cross-sectional porosity of lotus-root-like fibers fabricated with different high voltages

\begin{tabular}{cccc}
\hline Samples & Lotus root-like Porosity $/ \%$ & Standard Deviation $/ \%$ & CV $/ \%$ \\
\hline $19 \mathrm{kV}$ & 22.64 & 2.99 & 13.21 \\
$20 \mathrm{kV}$ & 22.54 & 4.17 & 18.52 \\
$21 \mathrm{kV}$ & 23.92 & 3.17 & 13.24 \\
$22 \mathrm{kV}$ & 25.87 & 3.91 & 15.12 \\
$23 \mathrm{kV}$ & 23.02 & 4.10 & 17.82 \\
\hline
\end{tabular}

the cross-section porosity of neat PLA nanofiber was not much affected by the flow rate ratio of core/shell solution and voltage in the electrospinning process parameters.

\subsection{Oil Sorption Capacity}

As shown in Table 5, the oil sorption capacity of the control sample (with lotus root-like structure) is $23.52 \pm 2.41 \mathrm{~g} / \mathrm{g}$, and that of the PLA nanofiber membrane (with lotus root-like and hollow structures) at $19 \mathrm{kV}$ is $13.94 \pm 3.44 \mathrm{~g} / \mathrm{g}$. The oil sorption capacity of the control sample is more than 1.5 times that of the hollow membranes, and there may be two reasons. 


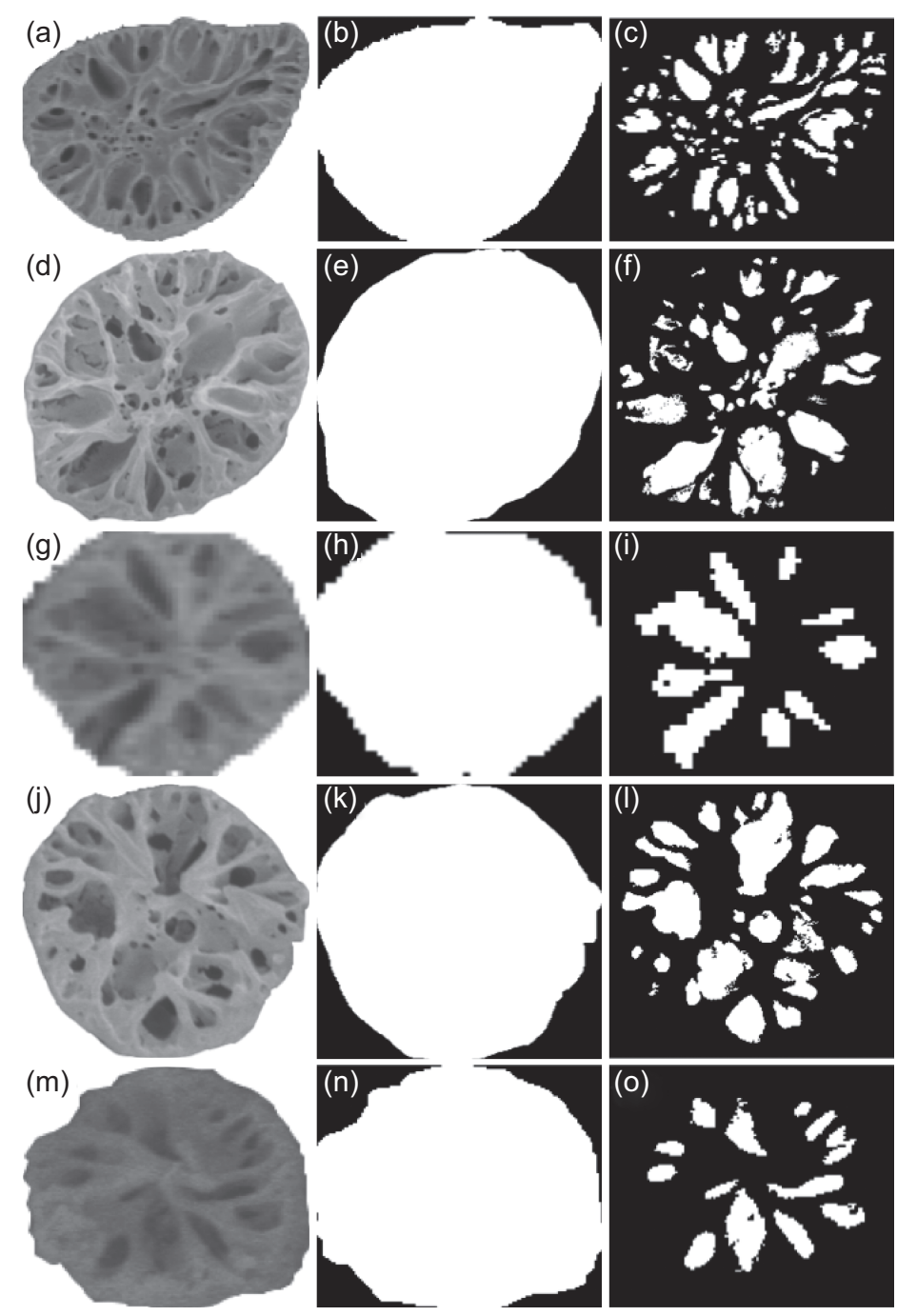

Fig. 6: Original (FE-SEM) and binarization of the cross-section with different high voltages, (a, b, c): $19 \mathrm{kV}$; (d, e, f): $20 \mathrm{kV}$; (g, h, i): $21 \mathrm{kV}$; (j, k, l): $22 \mathrm{kV}$; and (m, n, o): $23 \mathrm{kV}$. (a, d, g, j, m): FE-SEM images; $(b, e, h, k, n)$ : binarized images of the total area of the cross-section; (c, f, i, l, o): binarized images of porous structure

Table 5: Oil sorption capacity of lotus-root-like structure and hollow structure

\begin{tabular}{cccc}
\hline Samples & Oil Sorption Capacity $/ \mathrm{g} / \mathrm{g}$ & Standard Deviation $/ \mathrm{g} / \mathrm{g}$ & CV $/ \%$ \\
\hline Control Sample & 23.52 & 2.41 & 10.27 \\
$19 \mathrm{kV}$ & 13.95 & 3.44 & 24.65 \\
\hline
\end{tabular}

First of all, from the macro level, the control sample fluffy and surface viscosity are much larger than the hollow nanofiber membranes. In order to obtain hollow nanofibers, the core/shell PLA nanofiber membranes need to be immersed in deionized water for 48 hours. In this process, PLA hydrolyzed slowly in deionized water, and the water-soluble PVA dissolved in deionized water was likely to re-form a film on the surface of PLA, so that the fluffy and surface viscosity are greatly reduced. This can also be seen intuitively from Figure 7(b).

Secondly, from the microstructure, the ability of hollow fibers to adsorb oil is smaller than that 
of lotus root-like fibers, because the internal pore size of PLA nanofibers has a certain influence on the oil sorption capacity. The hollow fiber membrane has good connectivity, and the oil from one channel to enter, but will be very easy to ran out from another channel, so it can't trap diesel efficiently.
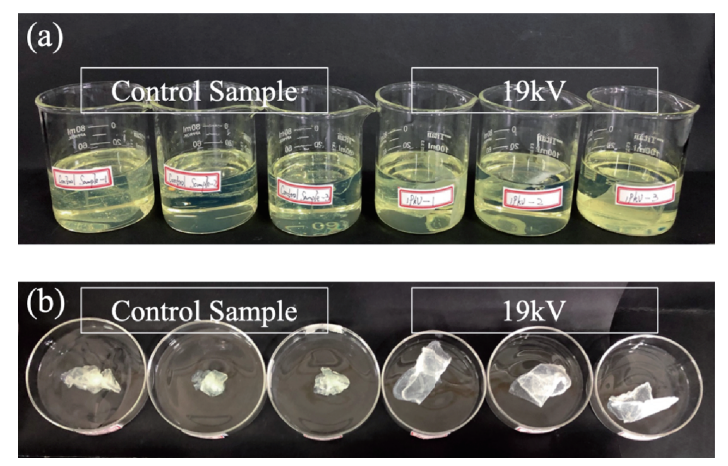

Fig. 7: Oil sorption diagram

\section{Conclusion}

In this paper, cross-sectional porosity of PLA nanofibers with hollow and lotus-root-like structures had been characterized scientifically and quantitatively.

When the flow rate ratio was $1: 3$, the high voltage was $23 \mathrm{KV}$, and the receiving distance was $12 \mathrm{~cm}$, the porous porosity was the smallest, which was $34.88 \% \pm 6.41 \%$. However, the spinning state under this parameter was the most stable. When the flow rate ratio was $1: 3$, the receiving distance was $12 \mathrm{~cm}$, and the high voltages were adjusted from $19 \mathrm{kV}$ to $22 \mathrm{kV}$, the porous porosity was about $41 \% \pm 2 \%$. From the $\mathrm{R}$ value and the number of small pores, we can find that the hollow structure of PLA nanofiber prepared in this work has general characteristics.

In the lotus-root-like fiber, the porosity values were around $23 \% \pm 2 \%$ at different electrospinning conditions, which means that the lotus-root-like porosity was not significantly affected by flow rate ratio of core/shell solution and voltage. All the pores prepared in this study are close to the ellipse, whether they are hollow pore and small pores in the hollow or the lotus-root-like fibers. Lotus-root-like fibers have 1.5 times the absorption capacity of diesel oil than hollow fibers. Although two possible reasons were highlighted, this phenomenon remains to be studied more deeply in the future.

\section{References}

[1] Jiang A, Pan Z. Cross-section Porosity of Porosity of Porous PLA Nanofibers with Hollow-structure [C]. Textile Bioengineering and Informatics Symposium Proceedings: 2019, 132-138.

[2] Sangeetha V H, Deka H, Varghese T O, et al. State of the art and future prospectives of poly(lactic acid) based blends and composites [J]. Polymer Composites, 2018, 39(1): n/a-n/a.

[3] Tachaphiboonsap S, Jarukumjorn K. Toughness and Compatibility Improvement of Thermoplastic Starch/Poly(lactic Acid) Blends [J]. Advanced Materials Research, 2013, 747: 67-71. 
[4] Pozo Morales A, Güemes A, Fernandezlopez A, et al. Bamboo-Polylactic Acid (PLA) Composite Material for Structural Applications: [J]. Materials, 2017, 10(11): 1286.

[5] Li Y, Lim CT, Kotaki M. Study on structural and mechanical properties of porous PLA nanofibers electrospun by channel-based electrospinning system [J]. Polymer: 2015; 56: 572-580.

[6] Wang Z, Zhao C, Pan Z. Porous bead-on-string poly(lactic acid) fibrous membranes for air filtration [J]. Journal of Colloid and Interface Science: 2015; 441: 121-129.

[7] Wang Z, Pan Z. Preparation of hierarchical structured nano-sized/porous poly(lactic acid) composite fibrous membranes for air filtration [J]. Applied Surface Science: 2015; 356: 1168-1179.

[8] Gu YQ, Wang Z, Sun Y, et al. Micro-scale PLA Fibrous Membranes for Adsorption of Cigarette Smoke [J]. Fibers and Polymers: 2018; 19 (3): 515-523.

[9] Liu H, Cao C Y, Wei F F, et al. Flexible macroporous carbon nanofiber film with high oil adsorption capacity [J]. Journal of Materials Chemistry A, 2014, 2(10): 3557.

[10] Huang C, Thomas N L. Fabricating Porous Poly(lactic acid) Fibers via Electrospinning [J]. European Polymer Journal, 2017: S0014305717316294.

[11] Sreekala M S, KoichiGoda, Devi P V. Sorption characteristics of water, oil and diesel in cellulose nanofiber reinforced corn starch resin/ramie fabric composites [J]. Composite Interfaces, 2008, 15(2-3): 281-299.

[12] Bandegi A, Moghbeli M R. Effect of solvent quality and humidity on the porous formation and oil absorbency of SAN electrospun nanofibers [J]. Journal of Applied Polymer Science, 2017, 135(1): 45586.

[13] Natália MT, Madrona GS, Ferreira FB, et al. High Performance of Asymmetric Alumina Hollow Fiber Membranes for the Clarification of Genipap (Genipa americana, L.) Fruit Extract [J]. Food and Bioprocess Technology: 2018; 1-12.

[14] Wang P, Chung TS. Exploring the spinning and operations of multibore hollow fiber membranes for vacuum membrane distillation [J]. Aiche Journal: 2014; 60 (3): 1078-1090.

[15] Wang P, Chung TS. Design and fabrication of lotus-root-like multi-bore hollow fiber membrane for direct contact membrane distillation [J]. Journal of Membrane Science: 2012; 421-422 (Complete): 361-374.

[16] Zhang SJ, Yu HQ, Feng HM. PVA-based activated carbon fibers with lotus root-like axially porous structure [J]. Carbon: 2006; 44 (10): 2059-2068.

[17] Lu H, Fan W, Huang Y, et al. Lotus root-like porous carbon nanofiber anchored with CoP nanoparticles as all-pH hydrogen evolution electrocatalysts [J]. Nano Research: 2017.

[18] Pakravan M, Heuzey MC, Ajji A. Core-Shell Structured PEO-Chitosan Nanofibers by Coaxial Electrospinning [J]. BIOMACROMOLECULES: 2012; 13 (2): 412-421.

[19] Alharbi HF, Luqman M, Fouad H, et al. Viscoelastic behavior of core-shell structured nanofibers of PLA and PVA produced by coaxial electrospinning [J]. Polymer Testing: 2018; 67. 